\title{
Why Leaders Fail in Introducing Values-Based Leadership? An Elaboration of Feasible Steps, Challenges, and Suggestions for Practitioners
}

\author{
Olli-Pekka Viinamäki ${ }^{1}$ \\ ${ }^{1}$ Public Management Faculty of Philosophy, University of Vaasa, Vaasa, Finland \\ Correspondence: Olli-Pekka Viinamäki, Public Management Faculty of Philosophy, University of Vaasa, PO box \\ 700, Vaasa FI-65101, Finland. Tel: 358-6-324-8414. E-mail: olli-pekka.viinamaki@uwasa.fi
}

Received: March 16, 2012

Accepted: April 1, 2012

Published: May 1, 2012

doi:10.5539/ijbm.v7n9p28

URL: http://dx.doi.org/10.5539/ijbm.v7n9p28

\begin{abstract}
The recent debate on modernizing leadership and organizations has placed a strong emphasis on values and ethics. This article elaborates on the benefits and challenges in the integration of values into leadership actions, most notably in regards to appraisals of Values-Based Leadership (VBL). The article contributes to a more specified understanding of the interrelation of stages in the VBL and the pitfalls in each step. A key argument is that if the critical issues and challenges in the introduction of the VBL are not identified, this would lead to unintended consequences in organizations, such as insignificant value-statements, inappropriate use of values, and illegitimate leadership practice. Contrary to many developmental suggestions of more virtuous and ethical or values-based leadership qualities, this article proposes leadership actions for leaders to undertake an effective, sound, and sustainablevalues-based leadership practices.
\end{abstract}

Keywords: values-based leadership, organizational values, values, ethics

\section{Introduction}

Over the last decade, much has been written about values, ethics, and integrity from a normative perspective, mostly suggesting what leaders should do and how leaders ought to behave. Both the positive and negative sides of many organizations and personal cases have been analyzed in order to develop a better understanding of ethics and values in leadership (Bass \& Steidlmeier, 1999; Cagle \& Baucus, 2006; Graber \& Osborne Kilpatrick, 2008; Buchko, 2007; Mussig, 2003; Pruzan, 1998). Accordingly, while efficiency and profitability are viewed as a leader's primary objectives, there is a long held view that leaders also have responsibility for ensuring standards of moral and ethical conduct (Barnard, 1938; Cullen, Victor \& Stephens, 1989; Resick, Hanges, Dickson \& Mitchelson, 2006).

Especially the Values-Based Leadership (VBL) evoked the role and importance of ethics and values in leadership (De Hoog \& Den Hartog, 2008; Treviño, Brown \& Hartman, 2003; Brown \& Treviño, 2006; Treviño, Weaver \& Reynolds, 2006). As a result, our knowledge about advances and pitfalls on the leadership forms and patterns has deepened. However, despite the lively academic and practical analysis, the question of getting a grip of challenges related to the VBL has become more critical. Especially, how we can identify problems in putting organizational values into practice and how different acts in leadership effect, for example, on organizational behavior and decision-making, problem solving in organization, motivation, and sustainable organizational leadership.

In these increasingly complex and ambiguous times, leaders and personnel are often unsure how to act and what to prefer. Messick and Bazerman $(1996,9)$ underline that: "Executives today work in a moral minefield. At any moment, a seemingly innocuous decision can explode and harm not only the decision maker but also everyone in the neighborhood.". Thus, to overcome troubles caused by 'only ends justify the means' philosophy which powers results-driven cultures, values and ethics may offer more predictable, stable, and sustainable base for leadership. As Moorman and Grover (2009) note ethics and values can provide a certain 'warranty' on integrity and future prospects in organizations. Moreover, ethics and values in leadership are thought to be uniquely important because of the impact leaders have on the conduct of others and on organizational performance and 
effectiveness as well as sustainability of leadership.

To address the better understanding of the VBL, this literature based article debates VBL by presenting a simplified three-step sketch, asking what problems leaders face in each step and why. Especially, if our desire is to integrate values into business and leadership, then to understand VBL as sequent parts or steps might be one potential perspective in terms of successful and sustainable leadership of organizations. Moreover, each step in the VBL highlights challenges what leaders may consider if they pursue towards a sound and effective VBL. In the conclusion, recommendations to avoid unexpected effects and ways to overcome highlighted challenges will be presented. In part, giving details to the VBL and discussing the potential pitfalls of VBL, it helps enhancing focus on ethics education and further leadership research.

\section{On Importance of Values-Based Leadership in Organizations}

Pruzan (1998, pp. 1379-1381) argues that we should actively introduce the notion of organizational and stakeholders' values into the leadership culture and develop a values-based perspective on management. Accordingly, Van Wart (1998, pp. 319) notes that the art of values management for practitioners has already become the leading skill necessary for private and public managers.

A reason why many leaders and academics has fascination on shared concept of values is because values are seen as the underlying attitudes and beliefs that help determine individual behavior, both personnel and leaders (Barnard, 1938, p. 279; Treviño \& Brown, 2004, p. 75). In such way, values are a means of influencing behaviors without the need to resort to formal structures, systems, strategies, or control mechanisms. Values would also provide a means of directing the organization in a desired way without having to resort to authoritarianism (Buchko, 2007, p. 38) and using tight or confusing rules (Mills \& Spencer 2005, p. 26). Moreover, the overall consensus seems to be that values are an important factor in the successful management of large organizations (e.g. Mintzberg et al., 2005; Hofstede, 2005) and in creating a competitive edge (Blanchard \& O'Connor, 1997).

As such, introducing values into business and leadership is not a new thought. The concept of values as central to organizations and organized societies has a long history in the sociology of organizations, as well as, to understanding guiding principles of institutions, organizations, and individuals (Schwartz, 1992; Cummings \& Worley, 2001).

Values-Based Leadership (VBL) refers to leadership based on foundational moral principles or values such as integrity, empowerment, and social responsibility (Reilly \& Ehlinger, 2007, p. 246). Brown and Treviño (2006, pp. 595) reviewed recent research that systematically conceptualizes VBL constructs and defined the VBL as "the demonstration of normatively appropriate conduct through personal actions and interpersonal relationships, and the promotion of such conduct to followers through two-way communication, reinforcement, and decision-making.". Brown, Treviño and Harrison (2005) add to this definition that it includes making the leader a legitimate and credible role model with normatively appropriate virtues such as honesty, trustworthiness, fairness, and care. The definition, as they observe it, implies also that values-based leaders should not only draw attention to ethics and make it salient in the organizational environment, but that they should also engage stakeholders and subordinates interpersonally in the process.

VBL also concerns to carry out well-known managerial functions; it is setting (ethical) standards and goals, rewarding on achieving desired outcomes (ethical conduct) and penalizing those who do not follow the standards (Treviño, Brown \& Hartman, 2003). Mussig (2003, pp. 73) argues that "values-driven leadership sets the function of the relationship as putting values into practice" and "the function of the leader may be to bring values to the relationship.". Others have noted the importance of shared values in creating a strong organization culture (Minztberg et al., 2005; Schein, 1985), motivating behavior by providing direction and emotional intensity to action (Schwartz, 1992), representing standards to judge and justify actions (Mills \& Spencer, 2005), and socialization activities and individuals to organization and leadership (Grojean et al., 2004).

A part of the VBL actions is to guide organizational members towards goals, which benefit the organization, its members, stakeholders, and society (Kanungo, 2001). In such, VBL is positively related to satisfaction with the leaders, perceived leader effectiveness, follower's job dedication and willingness to report ethical violations (Brown, Treviño \& Harrison, 2005). Some refer also the fact that introducing the VBL foster greater accountability, increased organization valuation, and gaining competitive edge, attracting and retaining staff and investors, and enhancing the organization's reputation within the corporate world (Buckley et al., 2001; Pruzan, 1998). In this vein, VBL is also criticized, because sometimes for instance, top executives might see ethics as "good business" in terms of enhanced image, reputation, and a source of competitive advantage (Buckley et al., 2001). 
Some studies of a values-based dimension of leadership have been embedded within the transformational, transactional and charismatic leadership domains (Bass \& Steidlmeier, 1999; Bass \& Avolio, 2000; Brown, Treviño \& Harrison, 2005). The relationships are not clear-cut, and the VBL likely use both transformational and transactional leadership approaches to influence followers' behavior (Treviño, Brown \& Hartman, 2003). Even though ambiguity of links, VBL tends to include similar inspirational motivation component that transformational leadership has (Bass \& Avolio, 2000). Treviño, Brown and Hartman (2003) found that VBL entails a transactional component that involves setting standards and expectations of ethical conduct for followers, hold their subordinates accountable using the rewards and punishment systems that are available (also Resick, Hanges, Dickson \& Micthelson, 2006).

\section{Sketching Steps for Values-Based Leadership and It's Unintended Outcomes}

As discussed above, there is evident need for the Values-Based Leadership (VBL). However, it is an ambiguous and challenging construct. To understand better the practice and execution of VBL, three simplified steps of VBL (Figure 1) are taken into consideration. The sketch presented in Figure 1 comes with combination of the existing models of Rest (1986), Treviño (1986), Jones and Ryan (1997) and Wittmer (2001) on the VBL and de Woot's (1996) model on change management.

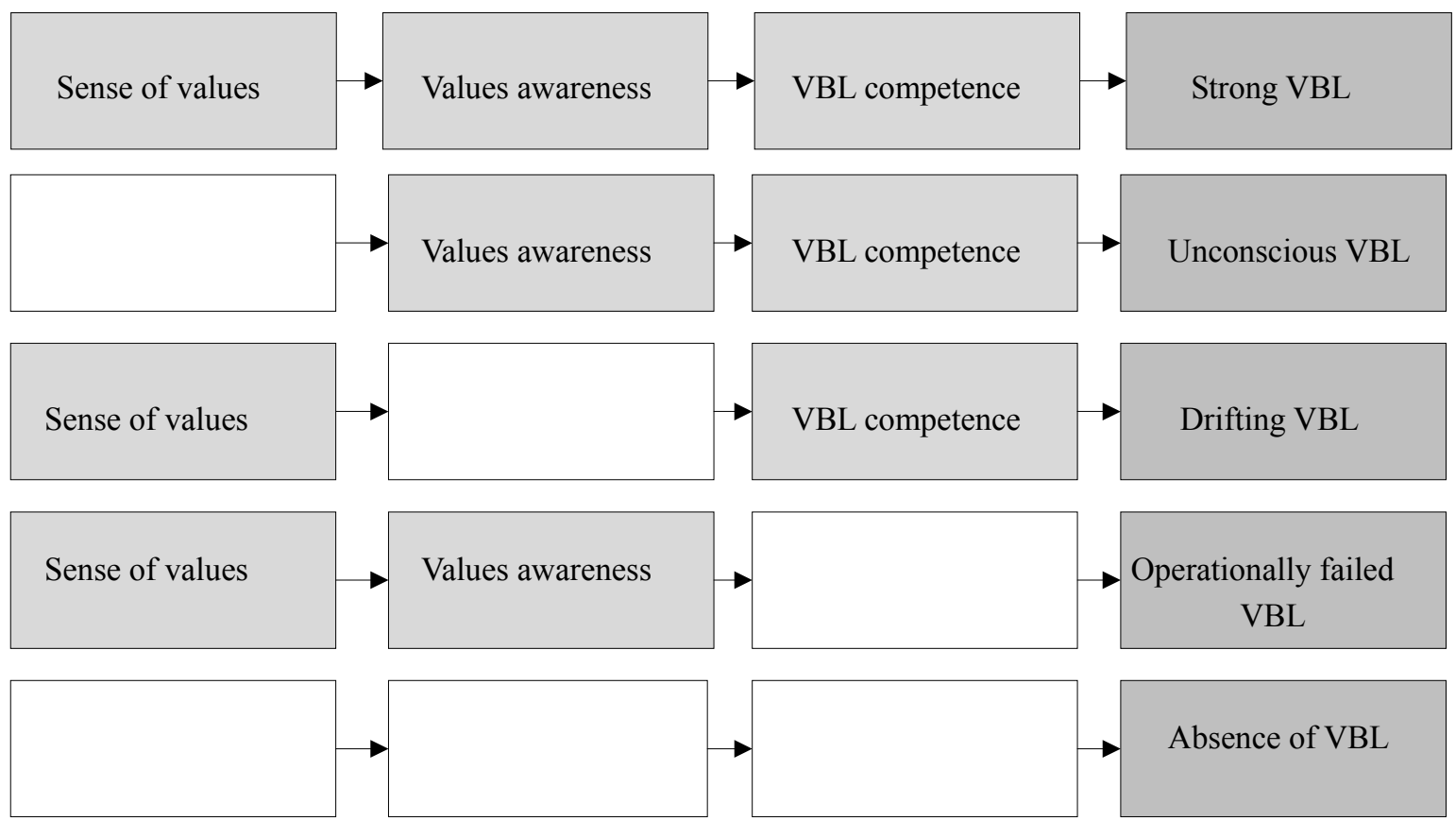

Figure 1. Steps of values-based leadership and anticipated outcomes

In figure 1, the upper line represents an ideal proceeding of VBL. The lines beneath illustrates situations (blank boxes) where one of the step is not taken into account, and the practice thereby leads some unintended outcomes in VBL. The lowest line represents situation where every leaders ignore every steps and aspects of VBL, and then apparent outcome is likely to be VBL, i.e. for instance, integrity violations, misbehaving the personnel, ignoring personal and organizational rules, values and virtues, unfair behavior, telling lies, disloyalty, etc.

In the following sections, the questions of how and why boxes are left blank are discussed in detail. Still, brief comments on each step can be made here. Sensitivity, particularly sense of values is the capability to recognize the values dimension in leadership, and this must take place before one can consciously engage his/her VBL. Otherwise, decision or judgment is made of other than values-based grounds. Values awareness refers here to judgment, especially to situations where values-based decisions are made. For instance, a leader decides what the "right" thing to do is. The third step, ethical competence is the drive to live in accordance with ethical principles and values, and apply them in daily situations, introduced in the values awareness step (Jones \& Ryan, 1997; Wittmer, 2001). No doubt, there are numerous content variables that influence the VBL process and leaders' behavior and managerial actions. Among those identified by researchers are individual, situational, organizational, legal, ethical, educational, gender, cultural and climate context variables (see Mencl \& May, 2009; McDevitt, 2007; Hood, 2003; Wittmer, 2000; Treviño, Weaver \& Reynolds, 2006; Treviño, 1986; Rest, 1986; Loe, Ferrell \& Mansfield, 2000). 
The three steps represent the consistent and widespread supported categories in VBL literature, consisting values sensitivity, sense of values, and ethical competence. In that sense, using these three steps are not entirely new, and as Jones (1991) and O'Fallon and Butterfield (2005) review of ethical leadership models show, although models' emphases and terminology differ, most models represent sequentially related components.

However, applying de Woot's (1996) model of change management which is not used in VBL field provides an idea to illustrate the proceeding of VBL with blank boxes. De Woot's (1996) schema helps us especially to reveal why each step is vital in VBL, and more importantly, why solving one step is not enough for overall success of VBL. For example, despite that leaders may tend to be very sensitive to ethical or value dilemmas, they might lack values awareness, and thereby end in a situation where any ethical or value principle tends to fit and be applicable. Similarly, leaders may have sense of values and great values awareness about the emerging issues, but they lack the skills to apply values in practice, i.e. VBL competence.

\subsection{Sense of Values}

"Recognizing a situation as an "ethical" one is the first, critical step in the process of ethical decision making. ... In short, ethical deliberation implies ethical detection." (Wittmer, 2000, p. 181). Sense of values is an important attribute because leaders must consider the welfare of others, both inside and outside the organization (Wittmer, 2000; Petrick \& Quinn, 1997; Rest, 1986). Sensitivity involves an interpretive process wherein the individual recognizes that organizational values or a moral principle is relevant to the circumstances (Rest, 1986).

More specifically, sense of values is a leaders' capacity "that enables professionals to recognize, interpret and respond appropriately to the concerns of those receiving professional services" (Weaver, Morse \& Mitcham 2008 , p. 607). Therefore, if one does not recognize an issue as having values, moral or ethical content, the value judgment in leadership process is not likely to be engaged (Brown \& Treviño, 2006), and thereby, we might end in a situation where we have a blank box in VBL (Figure 1). Then, an outcome can be that VBL is a series of unconscious acts. Of course, there are several issues that might cause this.

First, individually, our perceptive skills vary in giving values-based meaning to situations as a function of the complexity of factors involved and our own skills and abilities (Lord \& Maher, 1990; Wittmer, 2000). According to the social cognition theory, our individual perceptions make up the schema or lens through which we see the world (Fiske \& Taylor, 1984). “... a person who fails to recognize a moral issue will fail to employ moral decision-making schemata and will make the decision according to other schemata, economic rationality, for example" (Jones, 1991, p. 380). Caldwell et al. (2002) argue that leader's belief and values determine his/her values framework, but leadership traits, styles and situational factors also influence leader behaviors.

Secondly, a magnitude of consequences is important to sense of values (Brown \& Treviño, 2006), and especially, a leader's capacity to evaluate and to considerer consequences. Ethically intense situations draw observers' attention to leaders, and when intense situations are handled correctly, ethical intensity will generally be positively associated with perceptions of VBL. Jones (1991) also includes the magnitude of consequences of the act, but he adds that ethical intensity is a function of the issue-related moral imperative present in a moral situation. It varies with several factors: 1) the extent of social consensus that the act is moral/immoral, 2) the probability that the act will take place and cause the harm/good predicted, and 3) the social, cultural, physical, and psychological proximity of the victims of the act in question.

Thirdly, sometimes leaders are very well aware of values dimensions and are very sensitive to values-related or ethical issues, but still values is left outside leadership. What is striking in VBL and scandals in the corporate world is that, although all of the individuals reported reaching appropriate values sensitivity, only a few actually act on the basis value and ethical judgments and will act as whistle-blowers. There is a great variety of organizational, cultural and individual related factors, which occasionally explain wrong-doing or not choosing the "right thing" despite being readily apparent. Sometimes leader may enforce unethical acts or acts against shared values, but if an act was intended to benefit the organization at the expense of some third party, an attempt to rig a competitive bid, for example, the leader's decision might be judged in positive terms. (Jones \& Ryan, 1997).

Jones and Ryan (1997) use the term 'moral approbation' to describe the manifoldness how individuals recognize values-related issues and how this turn value or moral recognition into moral behavior. Basically, individuals derive arguments from five sources: philosophy, religion, biology, socialization, and cognitive development. However, the relative weights of each source are unknown and individuals have different philosophical and religious orientations. As well, they are biologically different and are socialized differently, but still, it seems that combination of forces from these five sources leads most individuals to seek moral approbation. Furthermore, 
one might argue that if a leader cannot recognize manifold grounds, he/she is likely miss the step of sense of values.

Leaders often compare their actual selves with their "ideal" selves (what they would like to be) and their "ought" selves (what they think they should be), and sometimes behave in a manner that reduces the discrepancy. Yet, part of the judgment in values sensitivity derives from organizational ethics, especially from codes of ethics, authority structures, and ethical culture on behavior. Some comes from individual, organizational, and group values, as well as, individual moral grounds, organizational policies and practices undertaken in organization. Still, they conclude that organizational life and leadership is too complicated to be interpreted in terms of a single aspect. (Jones \& Ryan, 1997.)

In the VBL, we may fail in this step if we are not able to particularize the source and magnitude of values-related issues (Weaver et al., 2008). Otherwise, the problem with values and recognizing them is just one of the issues that leaders and personnel have to cope with, and the issue acquires no ethical or values-related meaning. To particularize the issue requires interpretation which is based on social cognition and the leader's values and reasoning, as well matching the given interpretation with organization vision and strategy. When it is particularized, personnel and stakeholders often feel that the issue is taken into consideration.

\subsection{Values Awareness}

Values awareness is seen here as the second step in the VBL. As Treviño, Weaver and Reynolds (2006, pp. 954) refer to Rest's (1986) study where he observed that “once an individual becomes aware of an ethical issue, ethical judgment process should be more likely to be triggered". In other words, without sensitivity, situations and issues are not interpreted as values-grounded or we assume that no values dimensions are involved. Moreover, one might expect that an outcome of such a VBL where a we do not recognize the importance of values discretion (i.e. sense of values) but we do not have solid values-ground, the VBL might turn out as drifting and implying a mentality of 'anything goes' (cf. Figure 1). When values awareness exists in a leadership, values-based and moral reasoning (e.g. in Kohlberg's sense) become an "intentional, effortful, and controllable" process (Haidt, 2001).

Leaders demonstrate values awareness by having a concern for 1) the collective good of the group, 2) the impact of both means and ends, 3) the long-term and not just the short-term, and 4) the perspectives and interests of multiple stakeholders (Treviño, Brown \& Hartman, 2003). Leaders also have responsibility for instituting standards of ethical conduct and moral/organizational values that guide the behavior of followers, of course, alongside the greater emphasis given to productivity and financial objectives (Grojean, Resick, Dickson \& Smith, 2004), and these tasks require awareness of values-based dimensions.

Thus, it is obvious that values awareness is a complex issue in leadership. What particularly can cause a blank box in the second step in the VBL? A certain kind of start is Stephens and Lewin's (1992, pp. 2) argument that "Perhaps unethical choices in organizations are often made not because of human evil or unethicality, but because ethical decision making is cognitively complex and strongly affected by organizational design.". Jones and Ryan (1997) argue that leaders take their moral cues from their immediate peers or the larger society. Leaders are also limited in their capacity to process information and therefore rely on decision making heuristics to simplify the process, particularly in complex situations such as values-based judgment.

Treviño, Weaver and Reynolds (2006) argue that value-based judgment, which is often based on values awareness, is associated with several factors. First, values awareness has been strongly associated with age and education level, especially in terms of cognitive moral development (see also Weber, 1996). Secondly, they argue that particularly the type of harm and the magnitude of consequences tend to explain the intensity of values awareness. Thirdly, context is associated with values awareness. For instance, Weber (1990) finds that values awareness tend to be lower when individuals respond to work-related dilemmas compared to non-work dilemmas.

Moreover, Weaver et al. (2008) summarize six often pop-up difficulties in values awareness. They also provide ways to overcome difficulties: 1) Uncertainty, when values awareness is seeking other cues and viewpoints, examine personal vulnerabilities and challenge pre-existing conviction and new ideas; 2) Vulnerability, when in values awareness attention should be paid on ongoing contact with the client to identify cues and evoke deeper understanding of the client's experience; 3) Receptivity, which emphasizes that values awareness, is openness to learning from others. Receptivity is enhanced by freedom from competing obligations; 4) Responsiveness, which is in values awareness a sense of the demand of another's or anticipation of harm to the other. It is enhanced by having support from colleagues; 5) Courage, in values awareness is challenging fixed conceptions of responsibility and normality, placing values in tension with one another, and to assume responsibility for 
consequences; 6) Relationship, which increases possibilities to develop values awareness and recognize the unique, irreplaceable characteristics of customer and personnel.

Leaders are often held responsible for making codes and values visible and interpreting them if necessary. For example, Paarlberg and Perry (2007) found that managers play important role in interpreting broad strategic values into goals that are meaningful for employees in their daily work and routines. Leaders also have the primary role in communicating and demonstrating the true importance of ethical values to the organization's members (Grojean, Resick, Dickson \& Smith, 2004) and to motivate and commit personnel to ethics codes and organizational values.

Thus, as Grojean, Resick, Dickson, and Smith (2004) argue it is important for leaders to have awareness of personal values as they influence the choices they make and the behaviors in which they engage. To gain ethical-conscious leadership, it involves integration of personal ethical values and the needs of the stakeholders inside and outside of the organization, especially in the development of an ethical framework. This kind of focus requires that values is the cornerstone of how they conduct decisions and set strategies by practicing ethical behavior in their personal life, in their organizational duties, and in their relationships (Sims \& Brinkmann, 2002).

A utility of shared values and ethical codes according to Meglino and Ravlin (1998) is that if people hold similar value systems, this enables them to communicate more clearly, predict each other's behavior, and more efficiently to coordinate activities, resulting in reduced role conflict and ambiguity and increased satisfaction with the interpersonal relationship. Codes assist in raising the general level of awareness of values and ethical climate in organizations, but achieving a high level of awareness requires interpretation and communication of values and codes. Moreover, Paarlberg and Perry (2007, pp. 405) conclude that "organizations cannot influence employee behavior by communicating "the values of organization," as articulated by the top leadership through formal presentations or the distribution of laminated cards.". Just as important in understanding the impact of ethics initiatives and infrastructures on behavior, however, is the question of their integration with routine organizational functions (Weaver, Treviño \& Cochran, 1999).

Leaders not only directly influence the behavior of members, but their actions also influence the perceptions of members which lead to norms and expectation of appropriate conduct that become ingrained in the organization's climate (Grojean, Resick, Dickson \& Smith, 2004). Leader's actions both directly and indirectly establish the ethical tone of an organization by the actions that are encouraged, rewarded, and demonstrated. According to Brown et al. (2005) values-based leaders provide followers with voice, i.e. allowing followers a say in decision making and listening to their ideas and concerns. De hoogh and Den Hartog (2008) call this power sharing and employee empowerment. Treviño's et al. (1999) empirical data showed that the degree to which individuals openly talk about ethics in an organization is a good predictor of ethical conduct in that organization. Gortner (2001, pp. 524) adds that along with articulation goes sensitization which can help in developing mutual understanding, in creating a respect for the perceptions and ideas of others even though there is disagreement, and ultimately, in finding ways to solve the seemingly unresolvable.

However, there is a threat of overemphasizing values and ethics, as well as sanctions for misbehavior. Bartol and Locke (2000) suggest caution in using rewards to foster desired behavior, especially that personnel do not sacrifice the overall desired outcomes. Essentially, because of balancing organization's desired outcomes and ethics, leaders are responsible for engaging subordinates in in-group exchange activities to enact ethical codes. Despite the consensus that rewards and punishments have an impact on ethically relevant behavior the relationship of rewards and punishments to ethical behavior is not so simple. Often, introducing more sanctions or rewards does not lead to increase in ethical awareness (Treviño \& Youngblood, 1990). Sometimes leaders have to think about situation where weak sanctions can be worse for ethical behavior than no sanctions at all (Tenbrunsel \& Messick, 1999).

In addition, strong sense of values and ethics, values awareness may lead over-emphasizing their importance. If leaders pay attention to much that is wrong or bad, or what is according to values and what is not, managers capacity for focusing on those wrong or bad things which are 'really important' can significantly diminish. Thus, for leaders ethical awareness is necessarily selective. Some situations may even require that leaders operate in the moral sphere in a decisive and uncompromising way (Smilansky, 1996, p. 14-15).

Executives need courage, confidence, and moral strength to make unpopular decisions. When these leaders' traits are not tempered with modesty, openness, and integrity, ethical problems can arise. Messick and Bazerman (1996) list three illusions related to leader's personal characteristics and what leaders should re-evaluate. First, illusion of favorability in which the leader has an unrealistically positive view of the self. The challenge here is that 
leaders edit and filter information about themselves to maintain a positive image and undermine critics about their honesty, fairness and other ethical traits. Secondly, leaders might keep up the illusion of unrealistic optimism, where they believe themselves to be relatively immune from risks. Thirdly, the illusion of optimism is often supported by the illusion of control, especially that leaders feel that they are able to control the environment and their organization.

\subsection{Competence to Put Values into Practice}

Values awareness, including generally applicable principles, ethical codes, values and guidelines constitute the foundation of the moral orientation and are necessary in all external and internal actions of leadership in organizations. In real-life situations we have to be able to apply these general principles and act according to them.

However, it is seldom obvious what constitutes right or wrong (Kavathatzopoulos, 2003) and often there is no ready-made solution for emerging ethical problems. Instead, issues related to values are often encumbered by ambiguity. Therefore, leader actions that clarify ethical issues help to reduce ambiguity (Grojean, Resick, Dickson \& Smith, 2004, p. 229). In other words, it is argued here that being sensitive to value dilemmas and recognizing ethical issues in leadership, is not enough: they are just precursory steps to the third step, a competence to put values into practice.

What exactly is competence, especially competence to put values into practice? Kavathatzopoulos (2003) defines it as a psychological skill, a leader's ability to treat values conflicts in the best possible way for all parties concerned, knowing how to think, how to analyze actual cases, how to make decisions and how to solve problems on the basis of values. This may also hold quite well in the VBL. It also implies self-confidence and willingness to execute difficult decisions, and to support and sustain values-based positions. Furthermore, it illustrates that the leader has an ability to apprehend values-based situations and to realize responsibilities (Kälvemark Sporrong et al., 2007, p. 826), being aware of values and having consistent attitudes and the willingness to realize them (as proposed in Figure 1).

As for VBL competence, in most cases a leader's acts are weighted in terms how well he/she is able to interpret and communicate values and ethical codes to the personnel. Interpretation and communication are needed because even the individual's immediate peers or the top executives, as well as an espoused values and code of ethics could give conflicting or ambiguous signals (Jones \& Ryan, 1997). Often, organizational values are abstract, illustrating good and wanted outcomes and behavior, but they do not guide practitioners in particular tasks and efforts (Brytting \& Trollestad, 2000; Wittmer, 2001). Also, in situations where tasks are ill-defined, and standards of practice are not well established, interpretation of values provided by leaders is important (Brown, Treviño \& Harrison, 2005).

Employees align values through social processes and routine interactions between employees, managers, and customers and other stakeholders. In these processes, leaders and middle managers play key role in integrating individual values through the interpretation of strategic goals. A performance management system, an organizational structure, and control and rewards provide a formal opportunity to both articulate values and signify which employee values are important to the organization's mission (Paarlberg \& Perry, 2007).

One problem in the VBL competence is that leaders have difficulties to see the context of the problem, how to control the problem, or finding their own way to handle it. Then, the question is how to create functional problem-solving strategies and apply critical thinking, and still, follow organizational values. Yet, sometimes solutions may be antithetical to certain appreciated values in the organization. Still, in leadership one may come to the conclusion that it is necessary to violate a principle which one upholds strongly, in order to preserve something more important. Such ethical controversies heighten the complexity of the values competence and make the VBL much more difficult (Kavathatzopoulos, 2003; Smilansky, 1996).

It is strongly proposed in the literature that values-based leaders need a good image and legitimization, and they are especially weighted in real-life situations. Leaders are obligated to furnish a moral example for their subordinates and leaders are a central source of such guidance (Brown et al., 2005). Through role modeling, values-based leaders promote altruistic behavior and they can earn the confidence and loyalty of their followers. Role modeling influences employees via two routes: increasing trust in leaders, and facilitating value congruence (i.e. increasing 'fit' into the organization) (Grojean, Resick, Dickson \& Smith, 2004, p. 229).

In other words, leaders who demonstrate actions that are consistent with the organization's values and mission are likely to be viewed as more trustworthy. De Hoogh and Den Hartog (2008, p. 300) propose that employees will be more positive, hopeful, and optimistic about their organization and contribute to organizational success 
when their leaders act in an ethical manner. If the leader's moral integrity is in doubt, the leader will more likely fail to influence followers to achieve organizational goals (Kanungo, 2001). Weaver, Treviño and Agle (2005) found that if a leader is seen as an ethical role model at work, interviewed individuals associated characteristics such as willingness to turn mistakes into learning experiences and humility to ethical leadership. Moreover, as Jones and Ryan (1997, pp. 672) puts it, "human beings are very rarely physically forced to do anything. ... the personal costs of failure to comply with organizational directives can be quite high and agents may feel psychologically compelled to behave unethically.".

Role-modeling and successful cases representing that ethical conduct are needed because most lower-level employees in large organizations rarely interact with senior managers. Then, they must make inferences about the attributes of such leaders based upon available information (e.g. public relations information and organizational outcomes) and images rather than direct experience (Lord \& Maher, 1990). Even then in today's climate of high-profile business scandals, much attention focuses on the role top executives play in setting the ethical tone of their organizations and research also have demonstrated the importance of top management commitment in fostering ethical practices. But employees often are influenced most by their peers, groups, friends and immediate supervisors. Moreover, research has shown that top-down initiatives to foster organizational ethics are limited in impact (Weaver, Treviño \& Agle, 2005, p. 314).If a leader is only peripherally involved, or his role is modest, he may consider the situation as ethically distant because he will be judged less harshly than those who are directly involved or whose role is great (Jones \& Ryan, 1997).

Then, the question is how to influence the ethical quality of follower decisions if a leader is not physically present? In the research, several ways are presented. First, if values-based leaders represent attractive role models, but also in terms of their assigned role, their status, they are an important source of ethical guidance for their employees (Brown \& Treviño, 2006). Secondly, Brown and Treviño (ibid, p. 607) refer to Dukerich, Nichols, Elm and Vollrath's (1990) study that leader moral reasoning can influence moral reasoning in work groups. Thirdly, followers know that the leader will be holding them accountable for their decisions and will use rewards and discipline to do so (Brown, Treviño \& Harrison, 2005). Fourthly, Lord and Brown (2001) show that leaders can impact on man subordinate processes by influencing their self-concept. Here, leaders mediate culture and other exogenous factors as well as a range of psychological matching (i.e. observational learning, imitation, and identification), which in turn influence the subordinate's behavior.

Competence in the VBL is formed in a social context, thus there is a need to create arenas where the collective values competence of a workplace and among leaders can be maintained and developed (Kälvemark Sporrong et al., 2007). The attitudes and behaviors of peers in the workplace affect individuals' ethical behavior, with frequency and intensity of interaction peers make that influence stronger. De Hoogh and Den Hartog (2008, pp. 300) comment that too little attention has been given to top management teams in VBL. Top management team is involved in strategic decisions and directing the organization toward desired goals. If for example, despotic or self-interest guide working within a team, it gives a negative image for the rest of the organization. This also highlights the importance of values approval from one's peers and how other persons' ethical behavior serves as an influential role model for an individual's own ethical behavior in single situations. For that reason, sometimes despite an organization's efforts to highlight an executive's stance towards ethics, the role models people look to tend to be among those with whom they have close working relationships (Treviño, Weaver \& Reynolds, 2006). Thus, in leadership it is important to find and embed ethical practices and behaviors in the all processes and functions of the organization.

\section{Conclusion and Implication}

The discussion on the Values-Based Leadership (VBL) was declined here into three steps with emphasis on leaders' perspective which are needed in effective and sound values-based actions and leadership. It was asked how and why problems occur in VBL, and further, the idea of the blank boxes illustrated problems and pitfalls that we face in each step and which might accumulate as real problems in outcomes of VBL (cf. figure 1, section 3). The steps also illustrated the debate on the interrelation of steps.

In sum, three following conclusion are feasible. First, if sense of values is missing, the importance of values-based judgment or values dimensions is not taken into the consideration of the leadership, and therefore, leaders are not able to give ethical meaning for the issue. This follows that leaders are not capable of solving ethical problems. Discussions revealed that a key to better values sensitivity is related to the way how a leader is able to particularize and specify an ethical issue and share it with personnel.

Secondly, values awareness represented here a leader's consciousness of values and ethics, and the capabilities to fit them to organization's operations and strategies. If it is missing, leadership suffers from drifting without 
values and ethical principles; most values tend to fit, but choices and decisions cannot be restored to any of the appreciated values. Thus, to reach values awareness it requires choices and prioritizations between competing values and particularization of values in leadership goals and functions. Also, values awareness in leadership means that a leader constantly upholds key values and applies values and ethics in his/hers acts.

Thirdly, in VBL competence it is tested in practice how well leaders are able to use values and ethics in leadership. A common problem is that values and ethics are known, but they are not present in decision making or prioritizations. In sum, when values are applied in leadership, leaders should be receptive to various signals and have the ability to reflect and benchmark their decisions to former decisions. In the same way, leaders are responsible for giving operational meaning for abstract values and ethical principles and the coordination of value-intensive work in all organization. In addition, competence includes facilitation and mentoring of value-guided working and maintaining open dialogue on values and ethics.

Moreover, when difficulties are recognized in each step of VBL, it is possible to suggest some developmental actions to values-based leaders (see Table 1). The steps of VBL are at the left side, and some suggestions for the leaders are on the right side. Emphasis here is on leadership acts, not on virtuous or moral aspects of leadership and values/ethics. In other words, suggestions are presented for practitioners.

Table 1. Suggestions towards better values-based leadership practices

\begin{tabular}{ll}
\hline Steps of VBL & Suggestions for leaders' tasks. \\
\hline Sense of values & $\begin{array}{l}\text { Increase personnel's knowledge on values and ethics by using round-table } \\
\text { discussions. }\end{array}$ \\
& $\begin{array}{l}\text { Listen to stakeholders' needs and turn them into values and ethical principles. } \\
\text { Find a balance between enduring values and short-term operational goals. }\end{array}$ \\
Values awareness & $\begin{array}{l}\text { Create and facilitate discussions on persistent ethical principles and value } \\
\text { transformation. } \\
\text { Institutionalize values and ethical codes and procedures, especially when the } \\
\text { organization expands. }\end{array}$ \\
Incorporate values and ethics in strategically important functions and services, and \\
monitoring, feedback and evaluation systems. \\
values into practice \\
$\begin{array}{l}\text { Communicate values and create trust in ethical codes. } \\
\text { Coordinate competing values and find opportunities for consensus. } \\
\text { Operationalize values and provide task-specific and self-related feedback. }\end{array}$ \\
$\begin{array}{l}\text { Establish value-platforms in several levels of organization hierarchy where values } \\
\text { can be shared, debated, and agreed. }\end{array}$ \\
\hline
\end{tabular}

Further research is needed in order to understand ethical leadership benefits and pitfalls, and also how to institutionalize ethical leadership practices in a variety of organizations. Further studies would also be fruitful in investigating unintentional outcomes of VBL. Perhaps, using a multidimensional evaluation model and stakeholder approach would benefit the research, and help moving towards comprehensive constructions of VBL in organizations, and thereby, making values and ethics more familiar to a variety of stakeholders, not just the CEO-office business.

\section{References}

Aronson, E. (2001). Integrating Leadership Styles and Ethical Perspectives. Canadian Journal of Administrative Sciences, 18, 244-256. http://dx.doi.org/10.1111/j.1936-4490.2001.tb00260.x

Barnard, C. I. (1938). The Functions of the Executive. Cambridge: Harvard University Press.

Bartol, K. M., \& Locke, E. A. (2000). Incentives and Motivation. In S. L. Rynes, \& B. Gerhart (Eds.). Compensation in Organizations: Current Research and Practice (pp. 104-147). San Francisco: Jossey-Bass.

Bass, B.M., \& Avolio, B. (2000). Multifactor Leadership Questionnaire (2nd ed.). Redwood City, CA: Mind Garden.

Bass, B.M., \& Steidlmeier, P. (1999). Ethics, Character, and Authentic Transformational Leadership Behavior. Leadership Quarterly, 10, 181-217. http://dx.doi.org/10.1016/S1048-9843(99)00016-8

Brown, M. E. (2007). Misconceptions of Ethical Leadership: How to Avoid Potential Pitfalls. Organizational Dynamics, 36, 140-155. http://dx.doi.org/10.1016/j.orgdyn.2007.03.003 
Brown, M. E., Treviño L. K., \& Harrison, D A. (2005). Ethical Leadership: A Social Learning Perspective for Construct Development and Testing. Organizational Behavior and Human Decision Processes, 97, 117-134. http://dx.doi.org/10.1016/j.obhdp.2005.03.002

Brown, M. E., \& Treviño L. K. (2006). Ethical Leadership: A Review and Future Directions. The Leadership Quarterly, 17, 595-616. http://dx.doi.org/10.1016/j.leaqua.2006.10.004

Buckley, R. M., Beu, D. S., Frink, D. D., Howard, J. L., Berkson, H., Mobbs, T. A., \& Ferris, G. R. (2001). Ethical Issues in Human Resources Systems. Human Resource Management Review, 11, 11-29. http://dx.doi.org/10.1016/S1053-4822(00)00038-3

Cagle, J.A.B., \& Baucus, M.S. (2006). Case Studies of Ethics Scandals: Effects of Ethical Perceptions of Finance Students. Journal of Business Ethics, 64, 213-229. http://dx.doi.org/10.1007/s10551-005-8503-5

Caldwell, C., Bischoff, S. J., \& Karri, R. (2002). The Four Umpires: A Paradigm for Ethical Leadership. Journal of Business Ethics, 36, 153-163. http://dx.doi.org/10.1023/A:1014230002724

Cullen, J.B., Victor, B., \& Stephens, C. (1989). An ethical Weather Report: Assessing the Organization's Ethical Climate. Organizational Dynamics, 18, 50-62. http://dx.doi.org/10.1016/0090-2616(89)90042-9

De Hoogh, A. H. B., \& Den Hartog, D. N. (2008). Ethical and Despotic Leadership, Relationships with leader's Social Responsibility, Top Management Team Effectiveness and Subordinates' Optimism: A Multi-Method Study. The Leadership Quarterly, 19, 297-311. http://dx.doi.org/10.1016/j.leaqua.2008.03.002

De Woot, P. (1996). Managing Change at University. Journal of the Association of European Universities, CRE-Action no 109.

Dukerich, J. M., Nichols, M. L., Elm, D. R., \& Vollrath, D. A. (1990). Moral Reasoning in Groups: Leaders Make a Difference. Human Relation, 43, 473-493. http://dx.doi.org/10.1177/001872679004300505

Fiske, S.T., \& Taylor, S.E. (1984). Social Cognition. New York: Random House.

Gortner, H. F. (2001). Values and Ethics. In Terry Cooper (Ed.). Handbook of Administrative Ethics (pp. 509-528). New York: Marcel Dekker.

Grojean, M. W., Resick, C. J., Dickson, M. W., \& Smith, B. D. (2004). Leaders, Values, and Organizational Climate. Examining Leadership Strategies for Establishing an Organizational Climate Regarding Ethics. Journal of Business Ethics, 55, 223-241. http://dx.doi.org/10.1007/s10551-004-1275-5

Haidt, J. (2001). The Emotional Dog and Its Rational Tail: A Social Intuitionist Approach to Moral Judgment. Psychological Review, 108, 814-834. http://dx.doi.org/10.1037/0033-295X.108.4.814

Hood, J. N. (2003). The Relationship of Leadership Style and CEO Values to Ethical Practices in Organizations. Journal of Business Ethics, 43, 263-273. http://dx.doi.org/10.1023/A:1023085713600

Jones, T. M. (1991). Ethical Decision Making by Individuals in Organizations: An Issue-Contingent Model. Academy of Management Review, 16, 366-395. http://dx.doi.org/10.1023/A:1023085713600

Jones, T. M., \& Ryan, L. V. (1997). The Link between Ethical Judgment and Action in Organizations: A Moral Approbation Approach. Organization Science, 8, 663-680. http://dx.doi.org/10.1287/orsc.8.6.663

Kanungo, R. N. (2001). Ethical Values of Transactional and Transformational Leaders. Canadian Journal of Administrative Sciences, 18, 265-275. http://dx.doi.org/10.1111/j.1936-4490.2001.tb00261.x

Kavathatzopoulos, I. (2003). The Use of Information and Communication Technology in the Training for Ethical competence in Business. Journal of Business Ethics, 48, 43-51. http://dx.doi.org/10.1023/B:BUSI.0000004366.08853.72

Kälvemark Sporrong, S., Arnetz, B, Hansson, M. G., Westerholm, P., \& Höglund, A. T. (2007). Developing Ethical Competence in Health Care Organizations. Nursing Ethics, 14, 825-837. http://dx.doi.org/10.1177/0969733007082142

Loe, T. W., Ferrell, L., \& Mansfield, P. (2000). A Review of Empirical Studies Assessing Ethical Decision Making in Business. Journal of Business Ethics, 25, 185-204. http://dx.doi.org/10.1023/A:1006083612239

Lord, R.G., \& K.J. Maher. (1990). Alternative Information-Processing Models and Their Implication for Theory, Research, and Practice. Academy of Management Review, 15, 9-28. http://dx.doi.org/10.2307/258103

Lord, R. G., \& Brown, D. J. (2001). Leadership, Values, and Subordinate Self-Concepts. The Leadership Quarterly, 12, 133-152. http://dx.doi.org/10.1016/S1048-9843(01)00072-8 
McDevitt, R., Giapponi, C., \& Tromley, C. (2007). A Model of Ethical Decision Making: The Integration of Process and Content. Journal of Business Ethics, 73, 219-229. http://dx.doi.org/10.1007/s10551-006-9202-6

Meglino, B. M., \& Ravlin, E. C. (1998). Individual Values in Organizations: Concepts, Controversies, and Research. Journal of Management, 24, 351-389. http://dx.doi.org/10.1177/014920639802400304

Mencl, J., \& May, D. R. (2009). The Effects of Proximity and Empathy of Ethical Decision-Making: An Exploratory Investigation. Journal of Business Ethics, 85, 201-226. $\mathrm{http} / / / \mathrm{dx}$. doi.org/10.1007/s10551-008-9765-5

Messick, D. M., \& Bazerman, M. H. (1996). Ethical Leadership and the Psychology of Decision Making. Sloan Management Review, 37, 9-22. http://dx.doi.org/10.1016/S1529-2096(01)03014-0

Moorman, R. H., \& Grover, S. (2009). Why Does Leader Integrity Matter to Followers? An Uncertainty Management-Based Explanation. International Journal of Leadership Studies, 5, 102-114.

O'Fallon, M. J., \& Butterfield, K. D. (2005). A Review of the Empirical Ethical Decision-Making Literature: 1996-2003. Journal of Business Ethics, 59, 375-413. http://dx.doi.org/10.1007/s10551-005-2929-7

Petrick, J.A., \& Quinn, J.F. (1997). Management Ethics: Integrity at Work. Thousand Oaks, CA: Sage Series in Business Ethics.

Pruzan, P. (1998). From Control to Values-Based Management and Accountability. Journal of Business Ethics, 17, 1379-1394. http://dx.doi.org/10.1023/A:1006079110633

Resick, C. J., Hanges, P. J., Dickson, M. W., \& Mitchelson, J. K. (2006). A Cross-Cultural Examination of the Endorsement of Ethical Leadership. Journal of Business Ethics, 63, 345-359. http://dx.doi.org/10.1007/s10551-005-3242-1

Rest, J. R. (1986). Moral Development: Advances in Research and Theory. Westport, CT: Praeger.

Sims, R. (2000). Changing an Organization's Culture under New Leadership. Journal of Business Ethics, 25, 65-78. http://dx.doi.org/10.1023/A:1006093713658

Sims, R., \& Brinkmann, J. (2002). Leaders as Moral Roles Models: The Case of John Gutfreund and Salomon Brothers. Journal of Business Ethics, 35, 327-338. http://dx.doi.org/10.1023/A:1013826126058

Smilansky, S. (1996). The Ethical Dangers of Ethical Sensitivity. Journal of Applied Philosophy, 13, 13-20. http://dx.doi.org/10.1111/j.1468-5930.1996.tb00145.x

Stephens, C. U., \& Lewin, A. Y. (1992). Bounded Morality: A Cross-Level Model of the Determinants of Ethical Choice in Organizations. In Dean C. Ludwig and Karen Paul (Eds.).Contemporary Issues in the Business Environment. Vol. 8. Lewiston/Queenston/Lampeter, Wales: Edwin Mellen Press.

Tenbrunsel, A. E., \& Messick, D. M. (1999). Sanctioning Systems, Decision Frames, and Cooperation. Administrative Science Quarterly, 44, 684-707. http://dx.doi.org/10.2307/2667052

Treviño, L. K., Weaver, G. R., Gibson, D., \& Toffler, B. (1999). Managing Ethics and Legal Compliance: What Works and What Hurts. California Management Review, 41, 131-151.

Treviño, L. K., \& Youngblood, S. A. (1990). Bad Apples in Bad Barrels: a Causal Analysis of Ethical Decision Making Behavior. Journal of Applied psychology, 74, 447-476. http://dx.doi.org/10.1037/0021-9010.75.4.378

Treviño, L. K., Brown, M., \& Hartman, L.P. (2003). A Qualitative Investigation of Perceived Executive Ethical Leadership. Perceptions from Inside and Outside the Executive Suite. Human Relations, 56, 5-37. http://dx.doi.org/10.1177/0018726703056001448

Treviño, L. K., Weaver, G. R., \& Reynolds, S. J. (2006). Behavioral Ethics in Organizations: A Review. Journal of Management, 32, 951-990. http://dx.doi.org/10.1177/0149206306294258

Victor, B., \& Cullen, J.B. (1987). A Theory and Measure of Ethical Climate in Organizations. In W. C. Frederick (Ed.).Research in corporate social performance and policy: Empirical studies of business ethics and values. (pp. 51-71). Greenwich, CT: JAI Press.

Weaver, G. R., Treviño, L. K., \& Cochran, P. L. (1999). Integrated and Decoupled Corporate Social Performance: Management Values, External Pressures, and Corporate Ethics Practices. Academy of Management Journal, $42,539-552$. 
Weaver, G. R., Treviño, L. K., \& Agle, B. (2005). "Somebody I look Up to": Ethical Role Models in Organizations. Organizational Dynamics, 34, 313-330. http://dx.doi.org/10.1016/j.orgdyn.2005.08.001

Weaver, K. (2007). Ethical Sensitivity: State of Knowledge and Needs for Further Research. Nursing Ethics, 14, 141-155. http://dx.doi.org/10.1177/0969733007073694

Weaver, K., Morse, J., \& Mitcham, C. (2008). Ethical Sensitivity in Professional Practice: Concept Analysis. Journal of Advanced Nursing, 62, 607-618. http://dx.doi.org/10.1111/j.1365-2648.2008.04625.x

Weber, J. (1990). Managers’ Moral Reasoning: Assessing Their Responses to Three Moral Dilemmas. Human Relations, 43, 687-702. http://dx.doi.org/10.1177/001872679004300705

Weber, J. (1996). Influences upon Managerial Moral Decision Making: Nature of the Harm and Magnitude of Consequences. Human Relations, 49, 1-22. http://dx.doi.org/10.1177/001872679604900101

Wittmer, D. P. (2000). Ethical Sensitivity in Management Decisions: Developing and Testing a Perceptual Measure among Management and Professional Student Groups. Teaching Business Ethics, 4, $181-205$. http://dx.doi.org/10.1023/A:1009866315139

Wittmer, D. P. (2001). Ethical Decision-Making. In T. Cooper (Ed.). Handbook of Administrative Ethics, (2nd ed., pp. 481-507). New York: Marcel Dekker. 